Life, Death and Representation 


\section{Millennium-Studien}

zu Kultur und Geschichte des ersten Jahrtausends n. Chr.

\section{Millennium Studies}

in the culture and history of the first millennium C.E.

Herausgegeben von / Edited by

Wolfram Brandes, Alexander Demandt, Helmut Krasser,

Hartmut Leppin, Peter von Möllendorff

Band 29

\section{De Gruyter}




\title{
Life, Death and Representation
}

Some New Work on Roman Sarcophagi

\author{
Edited by \\ Jaś Elsner and Janet Huskinson
}

De Gruyter 
Diese Publikation wurde im Rahmen des Fördervorhabens 16TOA021 - Reihentransformation für die Altertumswissenschaften („Millennium-Studien“) mit Mitteln des Bundesministeriums für Bildung und Forschung im Open Access bereitgestellt. Das Fördervorhaben wird in Kooperation mit dem DFG-geförderten Fachinformationsdienst Altertumswissenschaften - Propylaeum an der Bayerischen Staatsbibliothek durchgeführt.

\section{(cc) BY-NC-ND}

Dieses Werk ist lizenziert unter der Creative Commons Attribution-NonCommercial-NoDerivatives 4.0 International Lizenz. Weitere Informationen finden Sie unter http://creativecommons.org/licenses/by-nc-nd/4.0/.

Die Bedingungen der Creative-Commons-Lizenz gelten nur für Originalmaterial. Die Wiederverwenung von Material aus anderen Quellen (gekennzeichnet mit Quellenangabe) wie z.B. Schaubilder, Abbildungen, Fotos und Textauszüge erfordert ggf. weitere Nutzungsgenehmigungen durch den jeweiligen Rechteinhaber.

ISBN 978-3-11-020213-7

e-ISBN 978-3-11-021678-3

ISSN 1862-1139

Library of Congress Cataloging-in-Publication Data

Life, death and representation : some new work on Roman sarcophagi / edited by Jaś Elsner and Janet Huskinson.

p. cm. - (Millennium-Studien ; Bd. 29)

Includes bibliographical references and index.

ISBN 978-3-11-020213-7 (hardcover : alk. paper)

1. Sarcophagi, Roman. I. Elsner, Jaś. II. Huskinson, Janet.

NB1810.L47 2010

$733^{\prime} .5-\mathrm{dc} 22$

2010028071

Bibliographic information published by the Deutsche Nationalbibliothek

The Deutsche Nationalbibliothek lists this publication in the Deutsche Nationalbibliografie; deatailed bibliographic data are available in the Internet at http://dnb.d-nb.de abrufbar.

(C) 2011 Walter de Gruyter GmbH \& Co. KG, Berlin/New York

Printing: Hubert \& Co. GmbH \& Co. KG, Göttingen

$\infty$ Printed on acid-free paper

Printed in Germany

www.degruyter.com 